\title{
Determining the Effectivity of Infrared Distance to Eliminate Dental Pain Due to Pulpitis and Periodontitis
}

\author{
Silvia Anitasari ${ }^{1,2}$ Deasy E. Wahab ${ }^{3}$ Barlianta Barlianta ${ }^{4}$ Hendrik S. Budi ${ }^{5,6} \bullet$ \\ ${ }^{1}$ Department of Dental Material and Devices, Dentistry Program, \\ Faculty of Medicine, Universitas Mulawarman, Samarinda, Indonesia \\ 2 Department of Microbiology, Faculty of Medicine, Universitas \\ Mulawarman Samarinda, Indonesia \\ ${ }^{3}$ Department of Health, Samarinda City Government, Samarinda, Indonesia \\ ${ }^{4}$ Department of Physiotherapy, Army Hospital, Samarinda, \\ Indonesia \\ ${ }^{5}$ Department of Oral Biology, Faculty of Dental Medicine, \\ Universitas Airlangga, Surabaya, Indonesia \\ ${ }^{6}$ Research Center, Faculty of Dental Medicine, Universitas Airlangga, \\ Surabaya, Indonesia \\ Eur J Dent:2020;14:360-365

\begin{abstract}
Address for correspondence Hendrik S. Budi, DDS, MDS, PhD, Department of Oral Biology, Faculty of Dental Medicine, Universitas Airlangga, Jl. Mayjend. Prof. Dr. Moestopo No. 47 Surabaya, 60132, Indonesia (e-mail: hendrik-s-b@fkg.unair.ac.id).
\end{abstract}

\begin{abstract}
Keywords

- dental pain

- infrared rays

- distance of light

- pulpitis

- periodontitis

Objective The infrared rays is one of the treatments to relief of dental pain due to pulpitis or periodontitis. The ability of infrared to increase the pain threshold which make eliminating $P$ substance on the inflammation area and inducing $A \beta$ and $A \delta$ fibers to activate $\gamma$-aminobutyrate (GABA) and neuropeptides to decrease the pain. Hence, reducing or eliminating dental pain. This study to get information about effectively distance between patients and infrared rays which can reduce or eliminate dental pain. Materials and Methods The explorative experimental research to determine the effectivity of the infrared rays' distance: 45,55 , and $55 \mathrm{~cm}$ in reducing or eliminating dental pain. The material of infrared was tungsten with luminous light and the time for the lighting was 15 minutes.

Statistical Analysis The data were obtained and analyzed using Wilcoxon's signed rank test and Kruskal-Wallis test ( $\alpha=0.05$ ).

Results There were influenced of the infrared rays to reduce the dental pain as follow, distance $45 \mathrm{~cm}(p=0.007)$, distance $55 \mathrm{~cm}(p=0.026)$, and distance $65 \mathrm{~cm}(p=0.007)$. The average scale reduction for distance $45 \mathrm{~cm}$ was $2.23 \pm 0.83$, the distance $55 \mathrm{~cm}$ was $3.33 \pm 0.87$, and the distance $65 \mathrm{~cm}$ was $(1.78 \pm 0.83)$. Therefore, according to Kruskal-Wallis test with $p=0.004(p<0.05)$ showed the significant difference between the scale to decrease of dental pain was the distance of 55 .

Conclusion Infrared rays located at a distance of $55 \mathrm{~cm}$ from patients might be more effective in relieving dental pain, compared with other distances tested.
\end{abstract}

\section{Introduction}

Dental pain is a condition that can be felt by all people and always be found in patients who visit the dentists. The pain involve uncomfortable emotion and sensory condition on the past due to pulpitis and periodontitis. It occurs when a stimuli penetrate into the teeth, as a thermal, chemical, or mechanic stimuli, but sometimes this pain can spontaneously occur without stimuli. ${ }^{1,2}$

Dental pain is sharp, localized, and short of duration. The hydrodynamic theory proposed by Brannstron and Astrom in 1964 is still currently accepted to explain the relationship 
between pain of dentinal origin and the displacement of odontoblast in the dentinal tubules. ${ }^{3}$ Thermal, physical, and chemical stimuli will cause the displacement of the pulp-dentinal fluid, thus stimulating the pulp nervous terminations. ${ }^{4}$

Type $A B$ and $A \delta$ fibers are responsible for dental pain and are probably activated by hydrodynamic mechanism. Therefore, their activation is directly associated to the presence of opened or occluded tubules and nerve activation may result in the release of neuropeptides from the activated nervous terminations and, consequently, induce neurogenic inflammation. ${ }^{5}$

Treatment for dental pain was influenced by subjectivity of every person. ${ }^{6,7}$ Basically, we decided to eliminate causative pathologic which responsibility by conservative, surgery therapy, or both of them. One of the conservative therapies to relief acute or chronic dental pain is infrared or heat therapy. ${ }^{8}$ Infrared is commonly used by physiotherapy and medical rehabilitation to reduce local and segmental inflammation based on gate control theory and a counter irritant method that intended to lessening discomfort condition or inflammation. ${ }^{9}$

The ongoing researches about infrared are developing rapidly since the invention of infrared laser technology and its growing utilization in dentistry, an additional therapeutic option is available for the treatment of dentinal pain. The laser, by interacting with the tissue, causes different tissue reactions, according to wavelength and distance between infrared laser and the target tissue. ${ }^{10,11}$

The laser photobiomodulation action in the dental pulp was reported with histological studies of dental pulp of mice after irradiation with laser, in teeth previously eroded with high rotation to expose the dentine. The profiling of the odontoblasts was observed, showing evidence of a large quantity of tertiary dentine production, causing the physiological obliteration of the dentinal tubules. The nonirradiated control teeth showed intense inflammatory process, and in some cases, evolved to necrosis. ${ }^{12,13}$

Infrared usually use tungsten material to the lamp with luminous light. The distance between patients and device are 45 to $60 \mathrm{~cm}$. The wavelength is $800 \mathrm{~nm}$ and perpendicular to the area of pain. The process of therapy takes time between 10 and 15 minutes and can be done repeatedly depending on the cases. ${ }^{8,9,14}$

There should be effective distance between device and the area of therapy but information found in the literature regarding the most effective distance can give the best result for it. Hence, this study aimed to determine the effective distance which yields the effective result.

\section{Materials and Methods}

\section{Ethical Procedures and Informed Consent}

This research obtained the ethical clearance of the Medical and Health research Ethics Commission, Faculty of Medicine, Mulawarman University (No.53/KEPK-FK/VI/2017). All patients signed the informed consent form for agreeing to participation before enrolling in the study.

\section{Study Design and Participants}

This research was conducted in a private dental clinic from January to July 2017, as double blind, randomized controlled trial and 36 patients were included of both the genders (age between 19 and 52 years) who were diagnosed as pulpitis and periodontitis patients. Patients who fulfilled the following criteria were included in the study ${ }^{1}$ : no photosensitive drugs ${ }^{2}$; no family history of porphyria ${ }^{3}$; no using immunosuppressive drugs ${ }^{4}$; no long-term anti-inflammatory drugs (ibuprofen) $)^{5}$; no using diuretics (furosemide) ${ }^{6}$; no using some antibiotics (ciprofloxacin, ofloxacin, and levofloxacin $)^{7}$; no pregnant ${ }^{8}$; age $>18$ years. After screening, block randomization was used, and the patients were randomly allocated to four groups through selection using sequentially numbered, ${ }^{1-4}$ opaque sealed envelopes at ratio of $1: 1: 1: 1$. The purpose of the study, the protocol, possible side effect, risks, and benefits of participation, all were informed to them.

\section{Preparation of Infrared Irradiation and Face Rating Pain Scale}

Each potentially eligible patient who visited the dental clinic during the treatment was examined by dentist responsible for the treatment. The patients were divided randomly into three groups and one control group as follow: group 1 received treatment with distance $45 \mathrm{~cm}$, group 2 received treatment with distance $55 \mathrm{~cm}$, group 3 received treatment with distance $65 \mathrm{~cm}$, and group 4 as a control no received treatment. All patients had one treatment used the infrared (Nesco SN 51;.Nesco Meblab;. Taiwan) with $800 \mathrm{~nm}$ wavelength and perpendicular to the area of pain for 15 minutes ( $\boldsymbol{- F i g}$. 1). They were analyzed pretreatment and posttreatment by Wong-Baker faces rating pain scale ( - Table $\mathbf{1}$ ). The following are the diagnostic criteria for the pulpitis and periodontitis.

\section{Pulpitis: ${ }^{15}$}

1. Intense, lingering pain to temperature changes.

2. Spontaneous pain.

3. Diffuse or referred pain.

4. Pain from cold test lingers more than 30 seconds.

5. May get pain from heat test.

6. May have spontaneous pain.

7. May be percussion sensitive.

8. Radiographic or clinically visible deep caries.

Periodontitis: ${ }^{16}$

1. Usually inflammation in the apical periodontium.

2. A painful response to biting, percussion, or palpation.

3. May or may not be accompanied by radiographic change (i.e., depending upon the stage of the disease, there may be normal width of the periodontal ligament or there may be a periapical radiolucency).

\section{Trial Flow}

After anamnesis and diagnosed, all patients got the therapy based on their groups (-Fig. 2). 


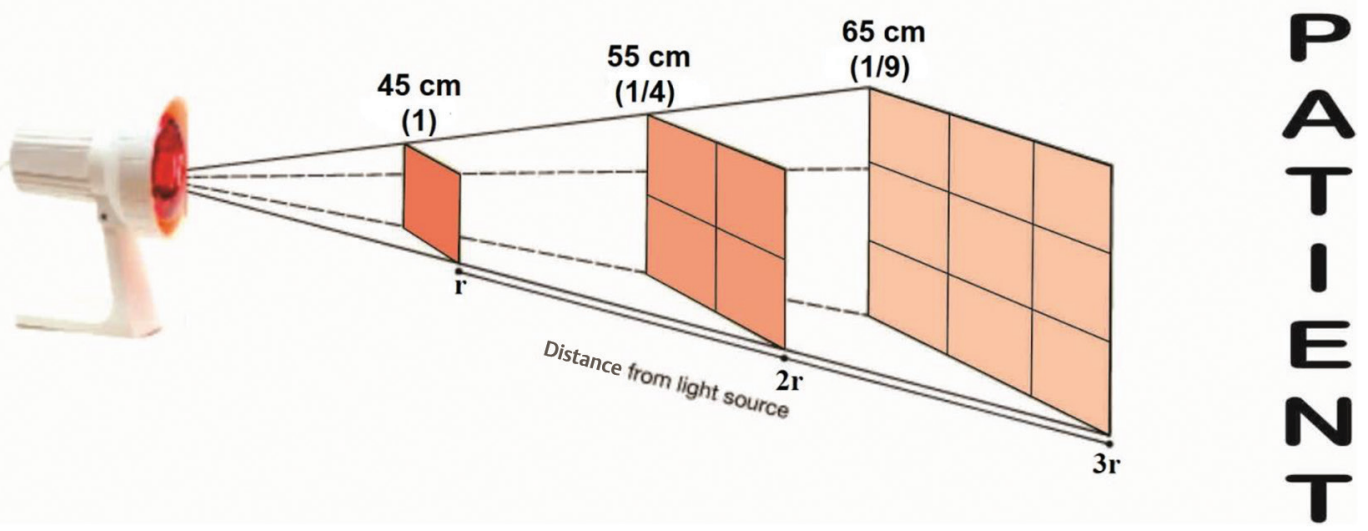

Fig. 1 The position and distance between infrared device and patients.

Table 1 Wong-Baker faces rating pain scale ${ }^{17}$

\begin{tabular}{|l|l|l|}
\hline Scale & Expression of Face & Description \\
\hline 5 & Happy & No hurts \\
\hline 4 & Little bit smile & Hurts little bit \\
\hline 3 & Neutral & Hurts little more \\
\hline 2 & Little bit sullen & Hurts even more \\
\hline 1 & Sullen & Hurts whole lot \\
\hline 0 & Crying & Hurts worst \\
\hline
\end{tabular}

\section{Statistical Analysis}

The difference between four groups were performed based on nonparametric statistics according to the Statistical Package for the Social Sciences (version 23.0; SPSS, Inc., Chicago, IL, United Sates) software. Data of pain scale were tabulated and analyzed in Wilcoxon's signed-rank test. The effectivity of distance of infrared therapy were analyzed using the Kruskal-Wallis test. For all analyses, the significance level was set at $0.05(\alpha=0.05)$.

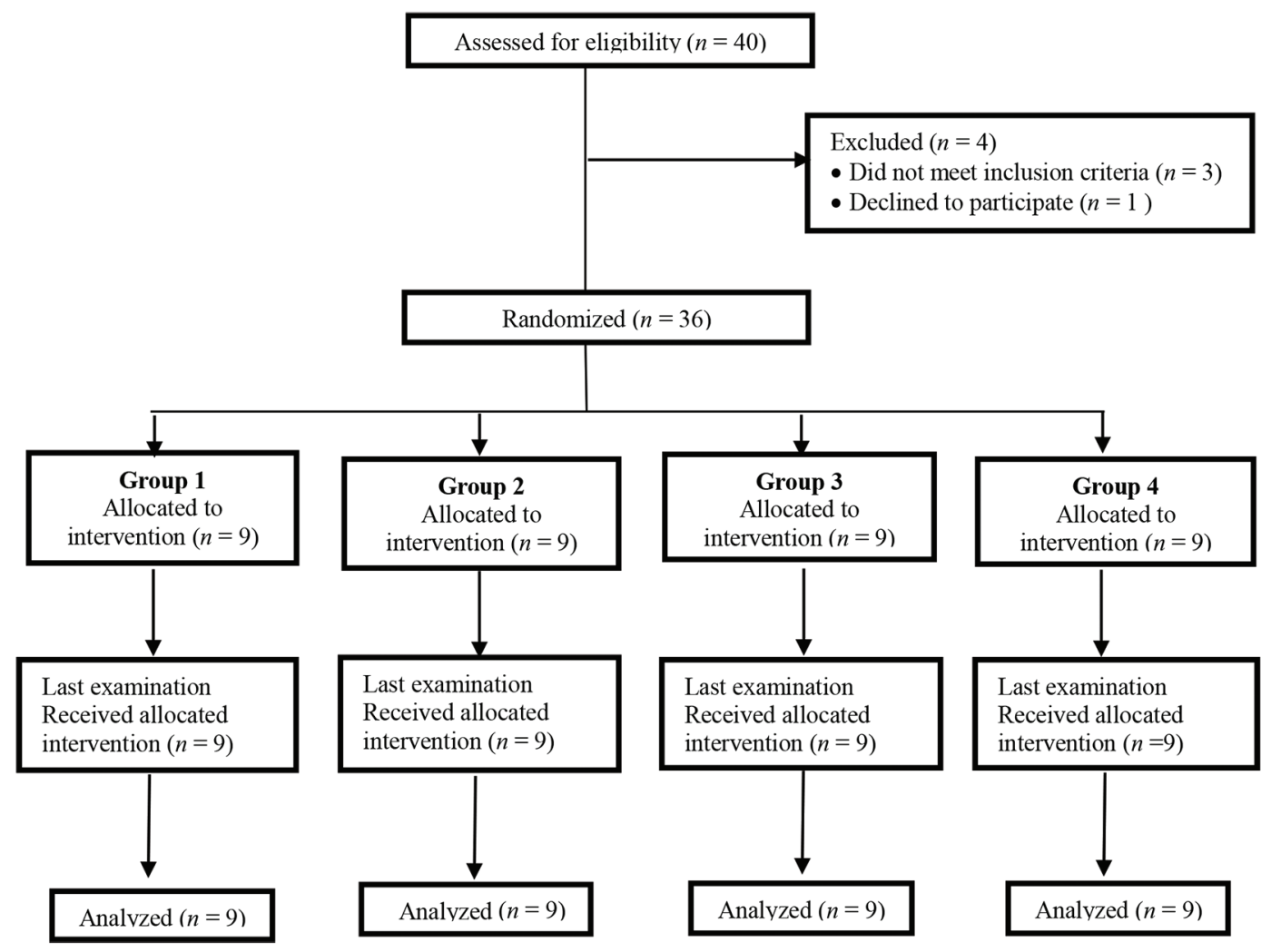

Fig. 2 Flow of study phases. 


\section{Results}

The data showed that there were reduced pain for all the patients who had infrared therapy with the distance 45,55 , and $65 \mathrm{~cm}$ based on Wong-Baker scale of pre and post-treatment (-Table 2). Data were analyzed using Wilcoxon's signed rank test $(\alpha=0.05)$.

The data ( - Table 3 ) showed that two patients experienced a decrease as much as 1 : pain scale lower (22\%), 2: pain scale lower for three patients (33\%), 3: pain scale lower for four patients (45\%), and all of them were treated by $45-\mathrm{cm}$ distance. The scale of decline for patients were treated by 55 -cm distance, 2 pain scale lower for one (11\%), 3 pain scale for four patients (45\%), 4 pain scale for three patients (33\%), and 5 pain scale for one patient (11\%). For the last distance, $65 \mathrm{~cm}$, there were four patients experienced a decrease of 1 level pain scale lower than before (45\%), 2 scale pain lower for three patients (33\%), and 3 scale pain lower for two patients (22\%).

The analysis of data on - Table 4 revealed significant difference between subjects who were treated by infrared with distance between 45,55 ,and $65 \mathrm{~cm}$, and the effective result was 55 -cm distance by Kruskal-Wallis test $(p<0.05)$.

\section{Discussion}

Our study proved that the distance of the infrared might be effective in reducing pain caused by pulpitis or periodontitis. Our assumption was based on the following scientific information that infrared treatment near the stellate ganglion results in the increase of blood flow velocity similar to that caused by stellate ganglion block and the infrared induces warmth in the treated areas. ${ }^{17-19}$

The infrared rays with wavelength of 600 to $1,600 \mathrm{~nm}$ are capable of reaching the subcutaneous tissue, following which the energy light is converted to thermal energy and produces warming sensation. Thermal energy can increase vasodilation of blood vessel and elasticity of connective tissue. The mechanisms involved in it may include increasing local blood flow and enhancing mild inflammatory reaction mediated through the release of histamine and prostaglandin, changing enzyme activity and metabolic rate, increasing pain threshold through a direct action of heat upon free nerve endings, or nerve trunk that supply the affected area of pain. ${ }^{20-22}$

The $A ß$ and $A \delta$ fibers respond to thermal energy and activate inhibitory neurotransmitter, such as $\gamma$-aminobutyrate

Table 2 Mean and standard deviation of dental pain relief pre and postinfrared therapy

\begin{tabular}{|l|l|l|l|}
\hline Group & Pretreatment & Post-treatment & $p$-Value \\
\hline Group 1 (D 45) & $1.44 \pm 1.24$ & $3.67 \pm 0.87$ & 0.007 \\
\hline Group 2 (D 55) & $1.00 \pm 1.80$ & $4 \pm 0.87$ & 0.026 \\
\hline Group 3 (D 65) & $1.44 \pm 1.01$ & $3.22 \pm 1.30$ & 0.007 \\
\hline Group 4 (control) & $1.89 \pm 0.78$ & $1.89 \pm 0.78$ & - \\
\hline
\end{tabular}

Abbreviation: $\mathrm{D}$, distance.

Note: There were significant differences within group $(p<0.05)$ on Wilcoxon's signed rank test.

Table 3 Infrared therapy effectiveness of dental pain

\begin{tabular}{|l|l|l|l|l|l|l|}
\hline \multirow{2}{*}{ Relief of pain scale } & \multicolumn{2}{|c|}{ D 45 } & \multicolumn{2}{c|}{ D 55 } & \multicolumn{2}{c|}{ D 65 } \\
\cline { 2 - 8 } & Total & $\%$ & Total & $\%$ & Total & \% \\
\hline 1 & 2 & 22 & 0 & 0 & 4 & 3 \\
\hline 2 & 3 & 33 & 1 & 11 & 3 & 22 \\
\hline 3 & 4 & 45 & 4 & 45 & 2 & 0 \\
\hline 5 & 0 & 0 & 3 & 33 & 0 & 0 \\
\hline Total & 0 & 0 & 1 & 11 & 0 & 9 \\
\hline
\end{tabular}

Abbreviation: D, distance.

Note: Relief of dental pain's subjects after infrared therapy $(n=9)$.

Table 4 Mean and standard deviation of decreasing dental pain scale $(n=9)$

\begin{tabular}{|l|l|l|l|l|}
\hline \multirow{2}{*}{ Group } & \multicolumn{2}{|c|}{ Relief of pain scale } & \multirow{2}{*}{$p$-Value } \\
\cline { 2 - 4 } & Min & Max & $\bar{X} \pm$ SD & \multirow{2}{*}{0.004} \\
\hline Group 1(D 45) & 1 & 3 & $2.23 \pm 0.83$ & \\
\hline Group 2 (D 55) & 2 & 5 & $3.33 \pm 0.87$ & $1.78 \pm 0.83$ \\
\hline Group 3 (D 65) & 3 & 3 & 0 & \\
\hline Group 4 (control) & 0 & 0 & 0 & \\
\hline
\end{tabular}

Abbreviations: D, distance; Min, minimal; Max, maximal; $\bar{X}$, mean; SD, standard deviation.

Note: There were significant differences among group $(p<0.05)$ on Kruskal-Wallis test. 
(GABA) and neuropeptide. All the inhibitory transmitters are conjugated on the neuron fibers and travel to dorsal horn of the spinal cord. The transmitters can decrease or block nociceptive transmission as not all signal are sent by the dorsal to the brain but most of the signals modulates the signal by themselves. Therefore, this condition can decrease the dental pain., 522

Our study represented the effectiveness of distance to relief of dental pain. The radiation with $55-\mathrm{cm}$ distance gives the effective result to decrease the dental pain compared between 45 and $65 \mathrm{~cm}$. It can be happened, because the Inverse Square Law says the intensity of light is proportional to the square of the distance from the light source. Based on this theory, the good distance was $45 \mathrm{~cm}$ but the statistical analysis showed the effective distance to be $55 \mathrm{~cm}$. This can happen, because there are many sensitive area on our face and based on a study by Nandraziova et al, the distance between lamp and skin could not be positioned closer to the skin without incurring the risk of a skin burn. ${ }^{23}$ Hence, the distance which is near the face cannot reduce the pain but increase it because of the undesirable heating that results from close proximity to the lamp and the erythema in the surface of skin. ${ }^{24,25}$ The other reason being, some patients cannot hold down the light. ${ }^{26}$

We illustrated this study, if the intensity of the nearest distance was $45 \mathrm{~cm}(r)$ that corresponded to a surface A. At a $2 r$ distance $(55 \mathrm{~cm})$, the same amount of energy passed through the surface $4 \mathrm{~A}$, making the intensity one-fourth, which indicates to the fact that the greater body surface area exposed to the light (infrared), the faster the pain declines. ${ }^{27}$ In this study, the highest intensity was $45-\mathrm{cm}$ distance but the greater body surface area exposed to the infrared was $65-\mathrm{cm}$ distance ( - Fig. 1 ). Theoretically, the greater body surface area exposed could decline the pain very well. However, our data showed that the $55 \mathrm{~cm}$ proximity from the infrared lamp could yield the best result compared to both 45 and $65 \mathrm{~cm}$. It was possible because the irradiation intensity was not influenced by the distance but it influenced the temperature of the area surface and could penetrate to the muscle $15 \mathrm{~mm}$ or more deeper. ${ }^{27-29}$ Therefore, the effective distance between infrared rays and the patient was $55 \mathrm{~cm}$ because this distance could decrease the dental pain, as well as muscle relaxation.

\section{Conclusion}

Application of infrared rays with $800-\mathrm{nm}$ wavelength was effective at $55-\mathrm{cm}$ distance for 15 minutes. This condition could change dental pain perception in its treatment.

\section{Conflict of Interest \\ None declared.}

\section{References}

1 Fernandes IB, Reis-Sá P, Gomes RL, Costa LR, Ramos-Jorge J, Ramos-Jorge ML. Factors associated with dental pain in toddlers detected using the dental discomfort questionnaire. J Indian Soc Pedod Prev Dent 2018;36(3):250-256
2 Cohen LA, Bonito AJ, Akin DR, et al. Toothache pain: behavioral impact and self-care strategies. Spec Care Dentist 2009;29(2):85-95

3 Braennstroem M, Astroem A. Study on the mechanism of pain elicited from the dentin. J Dent Res 1964;43(4):619-625

4 Lin M, Genin GM, Xu F, Lu T. Thermal pain in teeth: electrophysiology governed by thermomechanics. Appl Mech Rev 2014;66(3):0308011-3080114

5 Närhi M, Jyväsjärvi E, Virtanen A, Huopaniemi T, Ngassapa D, Hirvonen T. Role of intradental A- and C-type nerve fibres in dental pain mechanisms. Proc Finn Dent Soc 1992;88(1,suppl 1) :507-516

6 Won YS, Shim YS, An SY. The relationship between subjective oral health and dental fear in Korean adolescents. J Dent Anesth Pain Med 2017;17(4):289-295

7 Wideman TH, Edwards RR, Walton DM, Martel MO, Hudon A, Seminowicz DA. The multimodal assessment model of pain: a novel framework for further integrating the subjective pain experience within research and practice. Clin J Pain 2019;35(3):212-221

8 Kathuria V, Dhillon JK, Kalra G. Low level laser therapy: a panacea for oral maladies. Laser Ther 2015;24(3):215-223

9 Tsai SR, Hamblin MR. Biological effects and medical applications of infrared radiation. J Photochem Photobiol B 2017;170:197-207

10 Patil UA, Dhami LD. Overview of lasers. Indian J Plast Surg 2008;41(suppl) :S101-S113

11 Ansari MA, Erfanzadeh M, Mohajerani E. Mechanisms of laser-tissue interaction: II. Tissue thermal properties. J Lasers Med Sci 2013;4(3):99-106

12 Bidar M, Moushekhian S, Gharechahi M, Talati A, Ahrari F, Bojarpour M. The effect of low level laser therapy on direct pulp capping in dogs. J Lasers Med Sci 2016;7(3):177-183

13 Asnaashari M, Moeini M. Effectiveness of lasers in the treatment of dentin hypersensitivity. J Lasers Med Sci 2013;4(1):1-7

14 Deana NF, Zaror C, Sandoval P, Alves N. Effectiveness of lowlevel laser therapy in reducing orthodontic pain: a systematic review and meta-analysis. Pain Res Manag 2017;2017:8560652

15 Bender IB. Pulpal pain diagnosis-a review. J Endod 2000; 26(3):175-179

16 Barrington EP, Nevins M. Diagnosing periodontal diseases. J Am Dent Assoc 1990;121(4):460-464

17 Garra G, Singer AJ, Taira BR, et al. Validation of the Wong-Baker FACES Pain Rating Scale in pediatric emergency department patients. Acad Emerg Med 2010;17(1):50-54

18 Huang D, Gu YH, Liao Q Yan XB, Zhu SH, Gao CQ. Effects of linear-polarized near-infrared light irradiation on chronic pain. ScientificWorldJournal 2012;2012:567496

19 Liao CD, Tsauo JY, Liou TH, Chen HC, Rau CL. Efficacy of noninvasive stellate ganglion blockade performed using physical agent modalities in patients with sympathetic hyperactivity-associated disorders: a systematic review and meta-analysis. PLoS One 2016;11(12):e0167476

20 Vatansever F, Hamblin MR. Far infrared radiation (FIR): its biological effects and medical applications. Photonics Lasers Med 2012;4:255-266

21 Dong H, Yong HG, Qin L, Xue BY, Shai HZ, Chang QG. Effect of linear-polarized near-infrared light irradiation on chronic pain. ScientificWorldJournal 2012;2012:1-4

22 Nandraziova L, Matasova K, Gumulak R. Phototherapy and its effect on some physiological functions in newborn. Acta Medica Martiniana 2018;10(1):5-13

23 Cook HF. The pain threshold for microwave and infra-red radiations. J Physiol 1952;118(1):1-11

24 Douk HS, Aghamiri MR, Ghorbani M, Farhood B, Bakhshandeh $\mathrm{M}$, Hemmati HR. Accuracy evaluation of distance inverse square law in determining virtual electron source location in Siemens Primus linac. Rep Pract Oncol Radiother 2018;23(2):105-113 
25 Lentner A, Lintzen A, Wienert V. Quantification of Erythema following infrared-and water-filtered infrared-a-irradiation of the human skin. Phys Rehab Kur Med 1996;6(6):223-228

26 Barolet D, Christiaens F, Hamblin MR. Infrared and skin: Friend or foe. J Photochem Photobiol B 2016;155:78-85

27 Voudoukis N, Oikonomis S. Inverse square law for light and radiation. EJERS 2017;2(11):23-27
28 Goats GC. Appropriate use of the inverse square law. Physiotherapy 1988;74(1):8

29 Kruger W, Kelleher DK, Vaupel P. Infrared- a irradiation lamp with water filter: a new technical concept of a know physical principle and its application in physiotherapy. Phys Rehab Kur Med 1993;3(2):45-51 